


\title{
Roll of Planing in Health Developing as An İmportant Base in Urban Sustainable Development
}

\author{
Ahmad Shams Vahdati', Samad Shams Vahdati² \\ 'Student Of Phd In Geography And Urban Planning, Economics And Social Sciences, Tehran Payame Noor University,Tehran/Iran \\ ${ }^{2}$ Assistant Professor Of Emergency Medicine, Tabriz University Of Medical Science, Tabriz/Iran
}

Keywords: Roll, planing; health developing; Urban sustainable development

Aplication: 15.04.2013 Accepted: 30.05.2013

\section{Introduction}

Development is a comprehensive process of economical, social, cultural, and political activities aimed at frequently improving all peoples' life. Activity, freedom, appropriate participation, and justly distribution of resources are of its essential principles ${ }^{1}$.

In its extended concept, development means improvement of life level quality in all aspects which is beyond elevating of income level, providing better education and environment, improving nutrition and hygienic standards, lowering puberty, offering economical and social equality at higher levels, and taking benefit of richer cultural life? ${ }^{2}$.

Sustainable development is kind of development where poor and rich countries should protect natural environment during development process such that available resources or products are stably continued and maintained for us, our offspring, and future generations ${ }^{3}$.

Since introduction of sustainable development idea in
Stockholm Conference (1972), there were many controversies about its nature and how it can be achieved. It provides social just and guarantees capability of future generations to meet their requirements. Environment pollution and overuse of non-restorable natural resources may be introduced as main reason for emerging and developing of Sustainable development concept ${ }^{4}$.

Cities came into existence mainly aimed at developing desirable living places. Such places will be developed by appropriate labor and generative powers. Since unhealthy population cannot serve as generative labor force, fundamental quality of health should be regarded as essential rights of human being. Additionally, health standards should be improved as one of inseparable elements of a development holistic strategy ${ }^{5}$.

Therefore, some indexes including education, house and welfare facilities, social, and treatment and health indexes can be determined for urban stable development.

To maintain health and release from pain was one of the most important challenges of human being since 
far past. To meet the objective, human has used special strategies during different eras and considering scientific progresses and advancements to enhance penetration factor of treatment and health. Since human health and welfare is the final target of sustainable development, paying attention to the subject has been regarded as inevitable duties of governments since it has been introduced.

Health development means growth process of society health improvement such that it results in promotion of society welfare. It will lead to mitigate heavy load of the disease and fulfill mental and physical health related to satisfactory economical and social function. To realize such development, some measures should be considered including appropriate treatment and health planning, social services coordinating, treatment and health training, enough medical and paramedical human force training, developing of appropriate hospital and clinical services in cities and villages, and developing appropriate nursing and nutritive services.

Health indexes and criteria can be summarized in three following groups:

1- Society health status criteria

2- Health criteria

3- Criteria on how health services will be provided 6

Health criterion in a geographical area can be evaluated through taking statistics from epidemiologic diseases, determining life expectancy age, or measuring age structure. Health and service criteria can be measured through determining environmental conditions such as water health and soil resources or air pollution and studying regional facilities and capabilities, respectively.

Following indexes can be applied to offer criteria to evaluate health in a geographical area6.
1- Per capita physician for every one thousand person

2- Per capita dentist for every one thousand person

3- Number of hospital beds for every one thousand person

4- Per capita pharmacy for every one hundred thousand person

5- Per capita laboratory for every one hundred thousand person

6- Rural clinic for every fifty thousand rural population

7- Treatment and health unite to population ratio

8- Nutrition and mortality index of younger than one and four years old children

9- Reverse index of invalids and mortality rate of younger than 65 years person

10- Treatment insurance coverage percentage index

11- Per capita nurse and practice nurses for every 25 bed

Considering that realization of social justice and taking benefit of economical growth results by different classes of the society have been one of the main objectives of development planning ${ }^{7}$, paying attention to health and its indexes at different urban and rural regions leads to enhancement of social welfare and, therefore, decrease of diseases and the related expenses. So, the higher the health index, the lower the puberty in society. Since lowering puberty is known as the first step to meet Sustainable development in the third world countries, paying attention to health means promoting economical and social sites resulting in health development and enhancement as well as environment stability as the only shelter of human.

Basic steps can be taken to revive economical and social justice through proper planning on health subject in the developing countries and it can be realize through help of the governments and endeavor of health authorities. 


\section{References}

1. Artfield, Robin and Wilkins, Barry, International Justice and the Third World. London, Rutledge, 1992, P94

2. Rahimi H, Geography and sustainable development. Tehran, Oghlidos publisher, First edition, 2004, 321-7

3. Artfield, Robin and Wilkins, Barry, International Justice and the Third World. London, Rutledge, 1992, P93

4. Faturechi A. Barriers and challenges to achieving sustainable urban development. Payam-e-Ark Journal 2011;(30):58-66

5. Mardani Ghivi E. Towards a new paradigm of development. Political \& Economic Ettelaat 2003; (197)(198): 178-189

6. Rahimi H, Geography and sustainable development. Tehran, Oghlidos publisher, First edition, 2004, 102-82

7. Ardashir M. Sustainable development and urban management. Urban Management journal 2000; (3): 15-6 